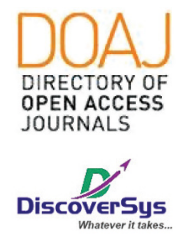

Published by DiscoverSys

\section{Therapeutic Approaches for Pusher Syndrome after a Stroke: a Literature Review}

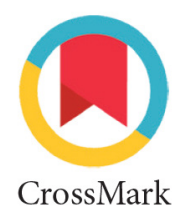

CrossMark

\author{
Sayu Aryantari Putri Thanaya ${ }^{1 *}$, Putu Eka Mardhika ${ }^{2}$
}

\title{
ABSTRACT
}

Introduction: Pusher syndrome is a disorder that is clinically present in 5-52\% of stroke patients, characterized by active pushing using the non-paretic side towards the paretic side, and resistance to the passive correction of posture. This disorder can pose an unfavorable effect on the rehabilitation of stroke patients. Hence, finding effective therapeutic approaches for pusher syndrome is crucial. This study aimed to identify the existing therapeutic approaches for pusher syndrome and investigate their effectiveness. Methods: A literature review was carried out, where studies were identified through searching the PubMed database from database inception to 2019 using the keywords: "pusher syndrome", "pusher behaviour", "contraversive pushing", "ipsilateral pushing", "lateropulsion", "physiotherapy", "physical therapy", "treatment", "therapeutic approach", "therapy" and "training". The literatures were analyzed systematically based on the results of previous studies.
Results: Several approaches were identified for treating pusher syndrome post-stroke, including robot-assisted gait training (RAGT), galvanic vestibular stimulation (GVS), visual feedback (VF), and physiotherapy with additional components such as relaxation therapy in the prone position and lateral stepping with body weight-supported treadmill training (LS-BWSTT). RAGT and VF training appear to be promising adjunctive approaches for treating pusher syndrome. Conventional physiotherapy with additional components such as relaxation therapy and LS-BWSTT have also led to positive effects. However, the effect of GVS has not been established.

Conclusion: There is evidence that some therapeutic approaches can be beneficial for improving pusher syndrome and outcomes of stroke patients, in particular when combined with conventional physiotherapy. However, the number of studies is still very limited. Further research with methodological rigor is needed.

Keywords: Physiotherapy, Pusher Syndrome, Therapeutic Approach

Cite This Article: Thanaya, S.A.P., Mardhika, P.E. 2019. Therapeutic Approaches for Pusher Syndrome after a Stroke: a Literature Review. Intisari Sains Medis 10 (2):452-458. D0I: 10.1556/ism.v10i2.507

'Department of Physiotherapy, Faculty of Medicine, Universitas Udayana, Bali, Indonesia ${ }^{2}$ Department of Neurosurgery, Faculty of Medicine, Universitas Udayana, Sanglah General Hospital, Bali, Indonesia

*Corresponding author: Sayu Aryantari Putri Thanaya; Department of Physiotherapy, Faculty of Medicine, Universitas Udayana, Bali, Indonesia; Email: sayuthanaya@unud.ac.id

Diterima : 2019-03-13

Disetujui : 2019-03-28

Diterbitkan : 2019-04-01

\section{INTRODUCTION}

Following a stroke, patients with hemiparesis commonly exhibit a loss of balance, typically falling towards the paretic side..$^{1-3}$ In an attempt to compensate this postural imbalance, these patients usually shift their body weight across the midline, away from the paretic side, and onto their nonparetic side. ${ }^{4}$ However, in 1985, Davies reported the behavior of a group of stroke patients who used their non-paretic extremities to push actively towards the paretic side and resist any effort at passive correction of their tilted posture. ${ }^{5}$ If left unsupported, these patients can continue to push themselves laterally until they experience a loss of postural balance, where they would fall on their paretic side. ${ }^{6}$ This behavior has been described as pusher syndrome, ${ }^{5}$ which is also known by the terms pusher behavior, ${ }^{2}$ contraversive pushing, ${ }^{1,7}$ ipsilateral pushing ${ }^{3,8}$ and lateropulsion. ${ }^{9}$

Pusher syndrome is still a largely unknown disorder that is clinically presented in $5-52 \%$ of patients who have suffered a stroke. ${ }^{8,10,11}$ Davies $^{5}$ suggested three important variables to identify pusher syndrome, namely: 1) spontaneous body posture, 2) increase of pushing force by spreading the non-paretic extremities and 3) resistance to the passive correction of posture. These three variables were then established in the form of a scale called the "Clinical Scale for Contraversive Pushing (SCP)" by Karnath et al. ${ }^{7}$ to aid clinicians in diagnosing pusher syndrome and measuring the severity of pusher syndrome. In addition to the SCP, several other clinical tools have been developed for examining pusher syndrome following a stroke, namely the Modified Scale for Contraversive Pushing ${ }^{12}$ and the Burke Lateropulsion Scale (BLS) ${ }^{13}$ Of these scales, the most extensively tested was the SCP, which had acceptable clinimetric properties. ${ }^{14}$

Patients with pusher syndrome tend to be stroke patients with the most severe impairments and functional limitations in gait, standing, and 
transfers, which hamper the rehabilitation process. ${ }^{4}$ Additionally, these patients also require a much longer time to regain functional independence. ${ }^{1,8}$ Pedersen et al. ${ }^{8}$ reported that patients with pusher syndrome need almost 3.6 weeks longer to reach the same levels of outcome than those without the syndrome. Consequently, finding effective therapeutic approaches is crucial to improve patient outcomes and shorten the duration of rehabilitation needed by patients. ${ }^{15}$

To date, there is a minimal amount of evidence about effective approaches for pusher syndrome. This literature review, therefore, aimed to identify the existing therapeutic approaches for pusher syndrome post-stroke and investigate their effectiveness.

\section{METHODS}

A literature review was carried out, where studies were identified through searching the PubMed database from database inception to 2019 using the keywords: "pusher syndrome", "pusher behaviour", "contraversive pushing", "ipsilateral pushing", "lateropulsion", "physiotherapy", "physical therapy", "treatment", "therapeutic approach", "therapy" and "training", combining with Boolean operators "OR" and "AND". Only full-text studies published in English were selected for inclusion in this review. A total of 10 papers were found related to this review's topic. A summary of the studies can be seen in Table 1.

\section{Therapeutic Approaches for Pusher Syndrome after a Stroke}

\section{Robot-assisted Gait Training (RAGT)}

RAGT has been shown to have a positive effect on gait ability, lower extremity functionality and balance in stroke patients. ${ }^{16-18}$ Accordingly, it has been suggested to be an alternative treatment for pusher syndrome.

In a single-blind randomized controlled trial, Bergmann et al..$^{19}$ investigated the effectiveness of RAGT on pusher syndrome in patients three weeks to six months post-stroke. In this study, patients in the experimental group received RAGT on the robotic-driven gait orthosis Lokomat for 60 minutes per session, while the control group received physiotherapy without robotic assistance for 60 minutes per session, which focused on postural control training, including sensory feedback components, encompassing active and dynamic exercises. Treatments were provided for five days per week for two weeks (8-10 sessions overall). After the treatments, the experimental group showed a significant reduction of pusher syndrome than the control group in both the SCP and BLS at post-test and follow-up than the control group. At post-test, 6 of 15 subjects in the experimental group and 1 of 15 subjects in the control group stopped showing pusher behavior. Moreover, it was found that 9 of 15 subjects in the experimental group and 5 of 15 subjects in the control group no longer demonstrated the behavior at follow-up.

Similarly, in another single-blind randomized trial, Yun et al. ${ }^{20}$ examined the effect of RAGT on the recovery of pusher syndrome in sub-acute stroke patients. Subjects were divided into an experimental group that received RAGT and a control group that received conventional physiotherapy. Patients received each treatment for 30 minutes per session, five days per week for a total of 3 weeks (total of 15 sessions). After the intervention, the experimental group demonstrated better improvements in the Burke Lateropulsion Scale (BLS) immediately after intervention and at four weeks follow-up. Moreover, the Berg Balance Scale (BBS) also improved significantly in the experimental group, and significant between-group differences were observed in the Postural Assessment Scale for Stroke (PASS) immediately after intervention and at four weeks follow-up.

In another study, Krewer et al. ${ }^{21}$ performed an observer-blinded cross-over pilot study to look at the immediate effects of GVS, machine-supported gait training with Lokomat and physiotherapy with visual feedback (VF) for the recovery of stroke patients with pusher syndrome. This study included patients with $(n=14)$ and without $(n=10)$ the diagnosis of pusher syndrome. After a singlesession of each specific intervention, the authors found that machine-supported gait training had a significant effect on the BLS score of patients compared to physiotherapy with VF, but no statistically significant difference was observed in the SCP score between the interventions.

\section{Visual Feedback (VF)}

Individuals with pusher syndrome have impaired postural vertical perception, yet their vertical visual perception is preserved.,22 For that reason, the use of visual feedback (VF) in physiotherapy was proposed to aid patients to become familiar with the misperception of their erect posture and help them learn movements that are needed to reach an upright body posture. ${ }^{6}$

The use of VF in the rehabilitation of patients with pusher syndrome has been investigated in several studies. ${ }^{10,21,23}$ Broetz et al. ${ }^{24}$ reported a case series of eight consecutively admitted acute stroke patients presenting with severe pusher syndrome who received physiotherapy using VF for 30 
minutes each day (six days per week) for 3.5 weeks. The authors found significant improvements in pushing behavior within three weeks; the overall SCP score significantly improved between days 4 and 24 post-stroke. In contrast to this, in a cross-over pilot study, Krewer et al. ${ }^{21}$ found that physiotherapy with VF component did not result in a significant change between the pre-test and post-test BLS values in pusher patients. Moreover, compared to physiotherapy with VF, they found that machine-supported gait had a significant effect on the BLS score of patients.

In another pilot randomized controlled study, Yang et al..$^{23}$ compared two different forms of VF training, namely computer-generated interactive VF training (experimental group) and mirror VF training (control group). Both groups received 20 minutes of training following 20 minutes of physiotherapy, three times a week for a total of three weeks. The findings showed both forms of VF training reduced the degree of pusher syndrome (decreased SCP score), improved balance (increased BBS score), and motor control of the lower limbs (increased FMA score). Furthermore, the experimental group exhibited significantly more significant improvements in the SCP and BBS compared to the control group.

\section{Galvanic Vestibular Stimulation (GVS)}

Another treatment approach that has been suggested for pusher syndrome is GVS, which uses low-amplitude direct electrical current that stimulates the vestibular system. This strategy has been successfully used to treat neglect syndrome in patients who have suffered a stroke (25) and can modify the perception of the vertical, ${ }^{26}$ so it was thought that GVS might be able to correct body tilt in pusher syndrome. ${ }^{21}$

Nakamura et al. ${ }^{27}$ reported a case series involving two stroke patients showing pusher syndrome. They investigated the effect of GVS combined with physiotherapy for pusher syndrome. The $\mathrm{ABAB}$ single-case design was used. In phases A1 and A2, the patients received 60-minute physiotherapy session five days a week. In phases B1 and B2, they underwent 20 minutes of GVS before each physiotherapy session and then performed the same physiotherapy program as in phases A1 and A2. The authors found that in both patients, the SCP scores were reduced only in phase B1. Although the BLS scores showed improvement at phase $\mathrm{A} 1$, a more considerable improvement was observed in both B phases. A cross-over pilot study conducted by Krewer et al. ${ }^{21}$ found that GVS therapy for 20 minutes did not lead to a significant change between the pre-test and post-test both the SCP and BLS values in pusher patients after a single therapy session.

\section{Physiotherapy with Additional Components}

Besides the specific approaches described above, several authors have reported the use of physiotherapy with additional components to improve outcomes of stroke patients with pusher syndrome. Paci and Nannetti ${ }^{28}$ reported a literature-based physiotherapy treatment in one pusher syndrome case, which included elements of somatosensory inputs and visual/auditory feedback. The patient received 27 therapy sessions over three weeks. Within a therapy session, the patient underwent a 2-hour physiotherapy session twice a day for five days a week and a one-hour session on Saturdays. The authors found that treatment sessions using visual/auditory feedback resulted in positive effects immediately, yet the immediate effects of somatosensory inputs were not seen. Nevertheless, the results were not maintained until the end of the study period.

Fujino and colleagues ${ }^{29}$ reported three case studies using a single-case study design (ABA) that looked at the effect of relaxation therapy in the prone position using a treatment table. In this study, patients received conventional physiotherapy, including sit-to-stand training, VF training and gait training using knee-ankle-foot orthosis, and relaxation therapy in the prone position for 10 minutes per day, which was conducted over six consecutive days. This study found that relaxation therapy in the prone position improved both SCP and BLS scores following the intervention phase, which continued until the follow-up phase.

A recent study by Pardo and Gallen ${ }^{30}$ described physiotherapy treatment interventions to improve pusher syndrome and functional outcomes in a case series involving five patients. Patients received 90 minutes of inpatient physiotherapy for an average of 19 days of inpatient treatment before being discharged. At discharge, all five patients exhibited improvements in pushing syndrome, balance, and transfer status.

In a case report, Romick-Sheldon and Kimalat ${ }^{31}$ provided treatment using lateral stepping with bodyweight supported treadmill training (LS-BWSTT) to encourage the subject to step laterally towards the uninvolved side. Following 11 sessions of inpatient treatment over 15 days, the subject showed reduced pusher syndrome and improvements in function. 
Table 1. Summary of studies included in this review

\begin{tabular}{|c|c|c|c|c|c|}
\hline Author & $\begin{array}{c}\text { Type of Study } \\
\text { and Sample Size }\end{array}$ & Protocol & Objective & $\begin{array}{c}\text { Main Outcome } \\
\text { Measures }\end{array}$ & Results \\
\hline $\begin{array}{l}\text { Bergmann et } \\
\text { al. }{ }^{19}\end{array}$ & $\begin{array}{l}\text { Single-blind } \\
\text { randomized } \\
\text { controlled trial ( } 15 \\
\text { experimental and } \\
15 \text { control) }\end{array}$ & $\begin{array}{l}5 \text { days per week for } \\
2 \text { weeks ( } 8 \text { to } 10 \\
\text { sessions overall) }\end{array}$ & $\begin{array}{l}\text { To determine the effect of } \\
\text { intensive RAGT on pusher } \\
\text { behavior compared to } \\
\text { non-robotic physiotherapy } \\
\text { (nR-PT). }\end{array}$ & $\begin{array}{l}\text { Primary outcome } \\
\text { measures: } \\
\text { SCP and BLS } \\
\text { Secondary outcome } \\
\text { measures: } \\
\text { POMA } \\
\text { FAC } \\
\text { SVV }\end{array}$ & $\begin{array}{l}\text { RAGT resulted in a larger } \\
\text { reduction of pusher } \\
\text { behavior than } \mathrm{nRP} \text { at } \\
\text { post-test }(\mathrm{SCP} \mathrm{p}=0.037 \\
\text { BLS: } \mathrm{p}=0.003) \text { and at } \\
\text { follow-up }(\mathrm{SCP} \mathrm{p}=0.008) \text {. }\end{array}$ \\
\hline Broetz et al. ${ }^{24}$ & $\begin{array}{l}\text { Case series } \\
\text { (8 pusher patients) }\end{array}$ & $\begin{array}{l}30 \text { minutes each } \\
\text { working day after } \\
\text { admission (six days } \\
\text { per week) for } 3.5 \\
\text { weeks. }\end{array}$ & $\begin{array}{l}\text { To evaluate physiotherapy } \\
\text { treatment using VF in cases } \\
\text { of severe contraversive } \\
\text { pushing. }\end{array}$ & SCP & $\begin{array}{l}\text { There were significant } \\
\text { improvements on the } \\
\text { overall score of the SCP } \\
\text { between days four and } 24 \\
\text { post-stroke }(p=0.026) .\end{array}$ \\
\hline Fujino et al. ${ }^{29}$ & $\begin{array}{l}\text { Case series } \\
\text { (3 patients) }\end{array}$ & $\begin{array}{l}10 \text { minutes a day } \\
\text { over } 2 \text { days. }\end{array}$ & $\begin{array}{l}\text { To investigate the effect } \\
\text { of relaxation therapy in a } \\
\text { prone position can reduce } \\
\text { pushing syndrome. }\end{array}$ & $\begin{array}{l}\text { SCP } \\
\text { Trunk control test } \\
\text { to measure truncal } \\
\text { balance }\end{array}$ & $\begin{array}{l}\text { Both SCP and trunk } \\
\text { control test scores } \\
\text { improved after the } \\
\text { intervention and at } \\
\text { follow-up. Additionally, } \\
\text { all patients could sit } \\
\text { independently. }\end{array}$ \\
\hline Krewer et al. ${ }^{21}$ & $\begin{array}{l}\text { Observer-blinded, } \\
\text { cross-over pilot } \\
\text { study } \\
\text { (14 pusher patients } \\
\text { and } 10 \text { control } \\
\text { patients without } \\
\text { pusher syndrome) }\end{array}$ & $\begin{array}{l}\text { Single-session } \\
\text { of each specific } \\
\text { intervention. }\end{array}$ & $\begin{array}{l}\text { To investigate the } \\
\text { immediate after-effects } \\
\text { of GVS, machine- } \\
\text { supported gait training } \\
\text { with the Lokomat, and } \\
\text { physiotherapy with } \\
\text { VF components in the } \\
\text { rehabilitation of patients } \\
\text { with pusher behavior. }\end{array}$ & $\begin{array}{l}\text { SCP } \\
\text { BLS }\end{array}$ & $\begin{array}{l}\text { Machine-supported gait } \\
\text { training had a significant } \\
\text { effect on BLS compared } \\
\text { to physiotherapy with VF } \\
\text { components but did not } \\
\text { have a significant effect on } \\
\text { SCP. GVS did not lead to } \\
\text { significant changes in both } \\
\text { scales. }\end{array}$ \\
\hline $\begin{array}{l}\text { Nakamura et } \\
\text { al. }{ }^{27}\end{array}$ & $\begin{array}{l}\text { Case series } \\
\text { (2 pusher patients) }\end{array}$ & $\begin{array}{l}60 \text { minutes therapy } \\
\text { session, } 5 \text { days a } \\
\text { week for } 4 \text { weeks. } \\
\text { In phases A1 and } \\
\text { A2, the patients } \\
\text { received a } 60 \text {-minute } \\
\text { physiotherapy } \\
\text { session five days } \\
\text { a week. In phases } \\
\text { B1 and B2, they } \\
\text { underwent } 20 \\
\text { minutes of GVS } \\
\text { before each } \\
\text { physiotherapy } \\
\text { session and then } \\
\text { performed the } \\
\text { same physiotherapy } \\
\text { program as in phases } \\
\text { A1 and A2. }\end{array}$ & $\begin{array}{l}\text { To investigate the feasibility } \\
\text { and effects of GVS } \\
\text { combined with physical } \\
\text { therapy for pusher behavior } \\
\text { in stroke patients. }\end{array}$ & $\begin{array}{l}\text { SCP } \\
\text { BLS }\end{array}$ & $\begin{array}{l}\text { In both patients, the SCP } \\
\text { scores were reduced only } \\
\text { during phase B2. Although } \\
\text { the BLS scores improved } \\
\text { at the A1 phase, a larger } \\
\text { improvement was seen at } \\
\text { the two B phases. }\end{array}$ \\
\hline
\end{tabular}




\begin{tabular}{|c|c|c|c|c|}
\hline $\begin{array}{l}\text { Paci and } \\
\text { Nannetti }^{28}\end{array}$ & $\begin{array}{l}\text { Case report } \\
\text { (1 pusher patient) }\end{array}$ & $\begin{array}{l}27 \text { therapy sessions } \\
\text { over } 3 \text { weeks. The } \\
\text { therapy consisted of } \\
\text { individual } 2 \text {-hour } \\
\text { physiotherapy twice } \\
\text { a day for } 5 \text { days a } \\
\text { week and a single } \\
\text { 1-hour session on } \\
\text { Saturdays. }\end{array}$ & $\begin{array}{l}\text { To describe a specific, } \\
\text { literature-based } \\
\text { physiotherapy treatment } \\
\text { and the outcome for a } \\
\text { stroke patient with pusher } \\
\text { behavior. }\end{array}$ & $\begin{array}{l}\text { - } \text { FMA } \\
\text { - } \text { The mobility } \\
\text { part of the Motor } \\
\text { Assessment chart } \\
\text { according to } \\
\text { Lindmark } \\
\text { - } \text { BI } \\
\text { - } \\
\text { - }\end{array}$ \\
\hline $\begin{array}{l}\text { Pardo and } \\
\text { Galen }^{30}\end{array}$ & $\begin{array}{l}\text { Case series } \\
\text { (5 pusher patients) }\end{array}$ & $\begin{array}{l}90 \text { minutes of } \\
\text { inpatient physical } \\
\text { therapy ( } 5 \text { days/ } \\
\text { week) }\end{array}$ & $\begin{array}{l}\text { To describe physiotherapy } \\
\text { treatment interventions } \\
\text { that reduce pushing } \\
\text { behavior and improve } \\
\text { functional outcomes } \\
\text { in patients with PS, } \\
\text { including regaining their } \\
\text { sense of midline (balance } \\
\text { and transfers), mobility } \\
\text { retraining, and neuro re- } \\
\text { education activities. }\end{array}$ & $\begin{array}{l}\text { Primary outcome } \\
\text { measures: } \\
\text { SCP } \\
\text { FIM transfer score } \\
\text { The balance was } \\
\text { assessed using a } \\
\text { clinical measure of } \\
\text { whether the participant } \\
\text { could sit unsupported } \\
\text { for at least } 1 \text { minute. }\end{array}$ \\
\hline
\end{tabular}

Immediate effects on the pusher behavior were observed when using visual and auditory feedback, but not when somatosensory input was used. These results were not maintained to the end of the treatment period. All five participants demonstrated improvements in pushing behavior, balance, and transfer status.
Secondary outcome measures:

CMSA

\begin{tabular}{ll}
\hline Romick- & Case report \\
Sheldon and & (1 pusher patient $)$ \\
Kimalat $^{31}$ &
\end{tabular}

Kimalat ${ }^{31}$

\begin{tabular}{ll}
\hline Yang et al. $^{23}$ & $\begin{array}{l}\text { Assessor-blinded, } \\
\text { pilot randomized } \\
\text { controlled study } \\
\text { (7 experimental } \\
\text { and 5 control) }\end{array}$
\end{tabular}

3 ti

SCP

BBS

FMA scale
SCP
FIM

BWSTT over 15 days treatment approach to FIM

during in-patient pusher syndrome using rehabilitation LS-BWSTT.

admission

20 minutes of

intervention

following 20 minutes

of regular physical

therapy

3 times a week for a

total of three weeks.
To investigate the effects

of a computer-generated

interactive VF training

The program compared

to mirror VF training

on the recovery from

pusher syndrome in stroke

patients.
The subject showed

decreased pusher syndrome and improved function after the intervention.

Both VF training

programs resulted in reduced severity of pusher syndrome, improved balance scores, and increased lower extremity motor control scores. Moreover, compared to mirror VF training, the computergenerated interactive VF training program led to significantly better improvement in pusher syndrome $(\mathrm{p}<0.01)$ and balance $(\mathrm{P}<0.05)$.

\begin{tabular}{|c|c|c|c|c|c|}
\hline Yun et al. ${ }^{20}$ & $\begin{array}{l}\text { A single-blinded, } \\
\text { randomized } \\
\text { controlled trial } \\
\text { (18 experimental } \\
\text { and } 18 \text { control) }\end{array}$ & $\begin{array}{l}1 \text { therapy session } \\
5 \text { days per week } \\
\text { for a total of } 3 \\
\text { weeks (total of } 15 \\
\text { sessions). Both } \\
\text { groups received each } \\
\text { treatment for } 30 \\
\text { minutes per session. } \\
\text { Moreover, both } \\
\text { groups received the } \\
\text { CPT for } 4 \text { weeks } \\
\text { after } 15 \text { sessions of } \\
\text { intervention. }\end{array}$ & $\begin{array}{l}\text { To investigate the effect of } \\
\text { RAGT on recovery from } \\
\text { lateropulsion compared } \\
\text { with CPT. }\end{array}$ & $\begin{array}{l}\text { Primary outcome } \\
\text { measures: } \\
\text { BLS } \\
\text { Secondary outcome } \\
\text { Measures: } \\
\text { BBS } \\
\text { PASS } \\
\text { SSEP }\end{array}$ & $\begin{array}{l}\text { The RAGT group showed } \\
\text { better improvements in } \\
\text { the BLS at T1 }(\mathrm{p}=0.032) \\
\text { and T2 }(\mathrm{p}<0.001) \text { than } \\
\text { the CPT group after the } \\
\text { intervention. Additionally, } \\
\text { the BBS improved } \\
\text { significantly in the RAGT } \\
\text { group at T1 ( }<<0.001) \text { and } \\
\text { T2 }(\mathrm{p}<0.001) \text {. Between- } \\
\text { group differences in the } \\
\text { PASS were significant } \\
\text { at } \mathrm{T} 1(\mathrm{p}=0.014) \text { and } \mathrm{T} 2 \\
(\mathrm{p}<0.001) .\end{array}$ \\
\hline
\end{tabular}

BBS: Berg Balance Scale; BI: Barthel Index; BLS: Burke Lateropulsion Scale; CPT: Conventional Physiotherapy; FAC: Functional Ambulation Classification; FIM: Functional Independence Measure; FMA: Fugl-Meyer assessment; GVS: Galvanic Vestibular Stimulation; LS-BWSTT: Lateral Stepping with Body Weight-Supported Treadmill Training; MAS: Modified Ashworth Scale; PASS: Postural Assessment Scale for Stroke; POMA: Performance-Oriented Mobility Assessment; RAGT: Robotassisted Gait Training; SCP: Scale for Contraversive Pushing; SSEP: Somatosensory Evoked Potentials; SVV: Subjective Visual Vertical 


\section{Summary and Future Directions}

The literature provides several approaches for treating pusher syndrome after a stroke, including RAGT, GVS, VF and physiotherapy with additional components such as relaxation therapy in the prone position and lateral stepping with body weightsupported treadmill training (LS-BWSTT). Based on the literature, RAGT or machine-supported gait training and VF training appear to be promising adjunctive approaches for treating pusher syndrome, although there are controversial results regarding the effect of VF training. There is also evidence to suggest that conventional physiotherapy with additional components such as relaxation therapy in the prone position and LS-BWSTT can also lead to positive effects. On the other hand, research on the use of GVS stated that GVS did not result in significant changes in pusher behavior.

Although there is preliminary evidence of decreased pusher syndrome following various therapeutic approaches, the findings of studies included this review should be treated with caution as it was evident that all studies lacked methodological rigor. Additionally, the studies included small to very small sample sizes (most were case reports or case series), which could be due to the low incidence of the disorder. In general, the number of published studies in this area is still small, which indicates that further research with larger sample sizes and sound methodology is needed.

\section{CONCLUSION}

Pusher syndrome in patients who have suffered a stroke is characterized by the act of active pushing using the non-paretic side towards the paretic side and resistance to the passive correction of posture. This disorder can pose an unfavorable effect on the rehabilitation of stroke patients. The results of this literature review indicate that some therapeutic approaches can be beneficial for improving pusher syndrome and outcomes of stroke patients, in particular when combined with conventional physiotherapy. However, the number of studies is still very limited. Further research in the form of randomized controlled trials with a longer followup periods is needed.

\section{CONFLICT OF INTEREST}

The author declared no potential conflicts of interest.

\section{FUNDING}

The author received no specific funding for this work.

\section{AUTHOR'S CONTRIBUTIONS}

SAPT was responsible for the conception of the work, conducting the literature search compiling the literature sources, drafting the manuscript, and constructing the whole of the manuscript. PEM was involved in the construction of the manuscript and reviewing the final manuscript.

\section{REFERENCES}

1. Karnath HO, Johannsen L, Broetz D, Ferber S, Dichgans J. Prognosis of contraversive pushing. J Neurol. 2002;249(9):1250-3.

2. Pérennou DA, Amblard B, Laassel EM, Benaim C, Hérisson C, Pélissier J. Understanding the pusher behavior of some stroke patients with spatial deficits: A pilot study. Arch Phys Med Rehabil. 2002;83(4):570-5.

3. Bohannon RW. Ipsilateral pushing in stroke. Archives of physical medicine and rehabilitation. 1996;77(5):524.

4. Roller ML. The 'pusher syndrome'. J Neurol Phys Ther. 2004;28(1):29.

5. Davies PM. Steps to Follow: A Guide to the Treatment of Adult Hemiplegia. New York: NY: Springer; 1985.

6. Karnath H-O, Broetz D. Understanding and Treating “Pusher Syndrome”. Phys Ther. 2003;83(12):1119-25.

7. Karnath HO, Ferber S, Dichgans J. The origin of contraversive pushing: Evidence for a second graviceptive system in humans. Neurology. 2000;55(9):1298-304.

8. Pedersen PM, Wandel A, Jørgensen HS, Nakayama H, Raaschou HO, Olsen TS. Ipsilateral pushing in stroke: Incidence, relation to neuropsychological symptoms, and impact on rehabilitation. The Copenhagen Stroke Study. Arch Phys Med Rehabil. 1996;77(1):25-8.

9. Pérennou DA, Mazibrada G, Chauvineau V, Greenwood R, Rothwell J, Gresty MA, et al. Lateropulsion, pushing and verticality perception in hemisphere stroke: A causal relationship? Brain. 2008;131(9):2401-13. DOI: 10.1093/ brain/awn170.

10. Lafosse C, Kerckhofs E, Troch M, Vereeck L, Van Hoydonck G, Moeremans M, et al. Contraversive pushing and inattention of the contralesional hemispace. J Clin Exp Neuropsychol. 2005;27(4):460-84. DOI: 10.1080/13803390490520463.

11. Abe H, Kondo T, Oouchida Y, Suzukamo Y, Fujiwara S, Izumi SI. Prevalence and length of recovery of pusher syndrome based on cerebral hemispheric lesion side in patients with acute stroke. Stroke. 2012;43(6):1654-6. DOI: 10.1161/strokeaha.111.638379.

12. Lagerqvist J, Skargren E. Pusher syndrome: Reliability, validity and sensitivity to change of a classification instrument. Adv Physiother. 2006;8(4):154-60. DOI: 10.1080/14038190600806596.

13. D’Aquilla MA, Smith T, Organ D, Litchman S, Reding M. Validation of a lateropulsion scale for patients recovering from stroke. Clin Rehabil. 2004;18(1):102-9. DOI: 10.1191/0269215504cr709oa.

14. Babyar SR, Peterson MGE, Bohannon R, Pérennou D, Reding M. Clinical examination tools for lateropulsion or pusher syndrome following stroke: A systematic review of the literature. Clin Rehabil. 2009;23(7):639-50. DOI: 10.1177/0269215509104172.

15. Paci M, Baccini M, Rinaldi LA. Pusher behaviour: A critical review of controversial issues. Disability and Rehabilitation. 2009;31(4):249-58. DOI: 10.1080/09638280801928002.

16. Hesse S, Tomelleri C, Bardeleben A, Werner C, Waldner 
A. Robot-assisted practice of gait and stair climbing in nonambulatory stroke patients. J Rehabil Res Dev. 2012;49(4):613-23. DOI: 10.1682/jrrd.2011.08.0142.

17. Cho DY, Park S-W, Lee MJ, Park DS, Kim EJ. Effects of robot-assisted gait training on the balance and gait of chronic stroke patients: focus on dependent ambulators. J Phys Ther Sci. 2015;27(10):3053-7. DOI: 10.1589/ jpts.27.3053.

18. Swinnen E, Beckwée D, Meeusen R, Baeyens J-P, Kerckhofs E. Does Robot-Assisted Gait Rehabilitation Improve Balance in Stroke Patients? A Systematic Review. Top Stroke Rehabil. 2014;21(2):87-100. DOI: 10.1310/tsr210287.

19. Bergmann J, Krewer C, Jahn K, Müller F. Robot-assisted gait training to reduce pusher behavior: A randomized controlled trial. Neurology. 2018;91(14):e1319-27. DOI: 10.1212/wnl.0000000000006276.

20. Yun N, Joo MC, Kim S-C, Kim M-S. Robot-assisted gait training effectively improved lateropulsion in subacute stroke patients: a single-blinded randomized controlled trial. Eur J Phys Rehabil Med. 2019;54(6):827. DOI: 10.23736/s1973-9087.18.05077-3.

21. Krewer C, Rieß K, Bergmann J, Müller F, Jahn K, Koenig E. Immediate effectiveness of single-session therapeutic interventions in pusher behaviour. Gait Posture. 2013;37(2):246-50. DOI: 10.1016/j.gaitpost.2012.07.014.

22. Karnath HO. Pusher syndrome - A frequent but littleknown disturbance of body orientation perception. Journal of Neurology. 2007;254(4):415-24. DOI: 10.1007/s00415006-0341-6.

23. Yang YR, Chen YH, Chang HC, Chan RC, Wei SH, Wang RY. Effects of interactive visual feedback training on post-stroke pusher syndrome: A pilot randomized controlled study. Clin Rehabil. 2015;29(10):987-93. DOI: $10.1177 / 0269215514564898$.

24. Broetz D, Johannsen L, Karnath HO. Time course of "pusher syndrome" under visual feedback treatment. Physiother Res Int. 2004;9(3):138-43. DOI: 10.1002/pri.314.
25. Utz KS, Dimova V, Oppenländer K, Kerkhoff G. Electrified minds: Transcranial direct current stimulation (tDCS) and Galvanic Vestibular Stimulation (GVS) as methods of noninvasive brain stimulation in neuropsychology-A review of current data and future implications. Neuropsychologia. 2010;48(10):2789-810. DOI:

26. Saj A, Honoré J, Rousseaux M. Perception of the vertical in patients with right hemispheric lesion: Effect of galvanic vestibular stimulation. Neuropsychologia. 2006;44(8):1509-12. DOI:

27. Nakamura J, Kita Y, Yuda T, Ikuno K, Okada Y, Shomoto K. Effects of galvanic vestibular stimulation combined with physical therapy on pusher behavior in stroke patients: a case series. NeuroRehabilitation. 2014;35(1):31-7. DOI: 10.1016/j.neuropsychologia.2010.06.002.

28. Paci M, Nannetti L. Physiotherapy for pusher behaviour in a patient with post-stroke hemiplegia. J Rehabil Med. 2004;36(4):183-5. DOI: 10.1080/16501970410029762.

29. Fujino $\mathrm{Y}$, Amimoto K, Sugimoto S, Fukata K, Inoue M, Takahashi $\mathrm{H}$, et al. Prone positioning reduces severe pushing behavior: three case studies. J Phys Ther Sci. 2016;28(9):2690-3. DOI: 10.1589/jpts.28.2690.

30. Pardo V, Galen S. Treatment interventions for pusher syndrome: A case series. NeuroRehabilitation. 2019;44(1):131-40. DOI: 10.3233/nre-182549.

31. Romick-Sheldon D, Kimalat A. Novel treatment approach to contraversive pushing after acute stroke: A case report. Physiother Canada. 2017;69(4):313-7. DOI: 10.3138/ ptc.2016-28

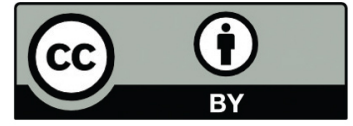

This work is licensed under a Creative Commons Attribution 